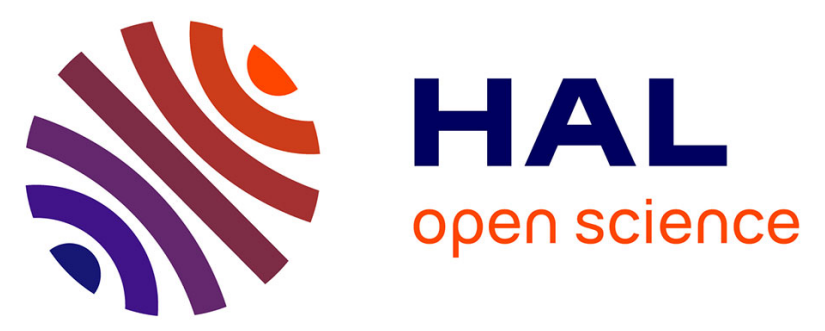

\title{
Sensitivity of Shielded Cable Transfer Impedance Measurement to Triaxial Cell Diameter
}

Oskari Leppäaho, Frédéric Lafon, Priscila Fernandez-Lopez, Marine

Stojanovic, Richard Perdriau, Mohammed Ramdani

\section{- To cite this version:}

Oskari Leppäaho, Frédéric Lafon, Priscila Fernandez-Lopez, Marine Stojanovic, Richard Perdriau, et al. Sensitivity of Shielded Cable Transfer Impedance Measurement to Triaxial Cell Diameter. 2021 IEEE International Joint EMC/SI/PI and EMC Europe Symposium, Jul 2021, Raleigh, NC, United States. pp.917-921, 10.1109/EMC/SI/PI/EMCEurope52599.2021.9559176 . hal-03440399

\section{HAL Id: hal-03440399 \\ https://hal.archives-ouvertes.fr/hal-03440399}

Submitted on 22 Nov 2021

HAL is a multi-disciplinary open access archive for the deposit and dissemination of scientific research documents, whether they are published or not. The documents may come from teaching and research institutions in France or abroad, or from public or private research centers.
L'archive ouverte pluridisciplinaire HAL, est destinée au dépôt et à la diffusion de documents scientifiques de niveau recherche, publiés ou non, émanant des établissements d'enseignement et de recherche français ou étrangers, des laboratoires publics ou privés. 


\title{
Sensitivity of Shielded Cable Transfer Impedance Measurement to Triaxial Cell Diameter
}

\author{
Oskari Leppäaho*, Frédéric Lafon*, Priscila Fernandez-Lopez*, Marine Stojanovic*, \\ Richard Perdriau $^{\dagger}$, Mohammed Ramdani ${ }^{\dagger}$ \\ *Valeo GEEDS, 2 rue André Boulle 94046 Créteil Cedex 02, FRANCE \\ oskari.leppaaho@valeo.com \\ †ESEO, 10 Boulevard Jeanneteau - CS 90717, 49009 Angers Cedex 1, FRANCE
}

\begin{abstract}
Triaxial measurement is an effective means to determine the transfer impedance of a shielded cable. It is based on coupled transmission line principle. In an ideal case, both transmission lines in the setup would be matched to guarantee the high frequency performance. In practice, matching is hard to achieve without compromising on usability and generality of the measurement setup. This paper discusses how triaxial cell diameter and the resulting impedance mismatch affects transfer impedance measurement results. In addition, the paper shows how impedance mismatches can be modeled, presents a simplified model to quickly understand the effects of impedance mismatch, and compares the model to results measured with different triaxial cell sizes. The simple model presented achieved similar accuracy to a more complex model defined in IEC 62153.

Index Terms-Electromagnetic compatibility, shielded cable, transfer impedance, triaxial measurement
\end{abstract}

\section{INTRODUCTION}

Shielded cable transfer impedance is a useful quantity for EMC engineers figuring out both emission and immunity characteristics of their systems. It represents shield's ability to block electromagnetic field propagation. There are both theoretical and experimental methods to determine transfer impedance. Schelkunoff published the theory almost a hundred years ago [1]. More recently, Warne et al. published an indepth theoretical derivation and formulation of generic transfer impedance [2], whereas Verpoorte et al. have done a review on commonly used transfer impedance models [3].

For shields with sufficient optical coverage, they model the transfer impedance

$$
Z_{T}=R_{T}+j \omega L_{T}
$$

as a sum of transfer resistance $R_{T}$ and transfer inductance $L_{T}$ ignoring the effect of transfer capacitance $C_{T}$. During experiments, transfer resistance can be either measured as DC resistance or determined from the low-frequency part of a frequency domain measurement. Transfer inductance is determined by fitting a $\mathrm{n}$ i nductance $\mathrm{v}$ alue $\mathrm{t}$ o $\mathrm{t}$ he frequency domain results. Fitting can be done either visually or by using mathematical methods. This simple approach works well for

The research leading to these results has received funding from the European Union's Horizon 2020 research and innovation programme under the Marie Skłodowska-Curie grant agreement No 812.790 (MSCA-ETN PETER). This publication reflects o nly $\mathrm{t}$ he a uthors' $\mathrm{v}$ iew, e xempting t he European Union from any liability. Project website: http://etn-peter.eu/. average shields, but good shields exhibit slightly different behavior. Their transfer inductance is so small that skin-effect becomes significant before the inductive portion of the transfer impedance, and thus needs to be modeled. The resulting drop in transfer resistance [4]

$$
R_{T}(f)=R_{T}(0) \frac{\gamma d}{\sinh (\gamma d)}
$$

is frequency dependent and is expressed as a function of the braid's propagation constant [5] $\gamma=(1+j) \sqrt{\pi f \mu \sigma}$, where $\sigma$ is conductivity of the braid wire, and the braid wire thickness $d$. However, the skin-effect phenomenon is more complex inside the braid and (2) tends to give too optimistic results. Thus, a modification $d^{\prime}=0.67 d / \sqrt{\cos \alpha}$, where $\alpha$ is the braid-wire angle, was developed based on experimental results [6]. In this paper, $d^{\prime}$ will be used.

Common experimental methods to measure transfer impedance were described and compared by Mushtaq et al. [7]. Models with different fidelity have been developed to analyze the behavior of these methods. Rotgerink et al. presented models for the two most-used methods: line-injection and triaxial [8]. The IEC technical specification [9] based heavily on Kley's work [10] recognizes two main high-frequency phenomena that affect the triaxial measurement accuracy: effect of infinitesimal couplings along the coupled transmission lines and the effect of wave propagation and reflection at imperfect terminations. A fairly complex equation is presented to take these effects into account together.

In this paper, the effects are separated and their relative importance is discussed in Section II. Then, a simplified model based on imperfect terminations is proposed. For that purpose, Test Methods B and C described in IEC 62153-4-3 are discussed [11]. The methods differ on the termination used for the CUT. In Section III, the results of this analysis are compared to measurement results.

\section{TRiaxial Tube Model}

Triaxial setups analyzed in here have two distinct sections in the outer circuit: the cable under test section and an impedance matched section as shown in Fig. 1. The impedance matched section is needed to provide space for the cable termination that is done inside the triaxial tube. To provide a simple model that would clearly illustrate physical phenomena happening 


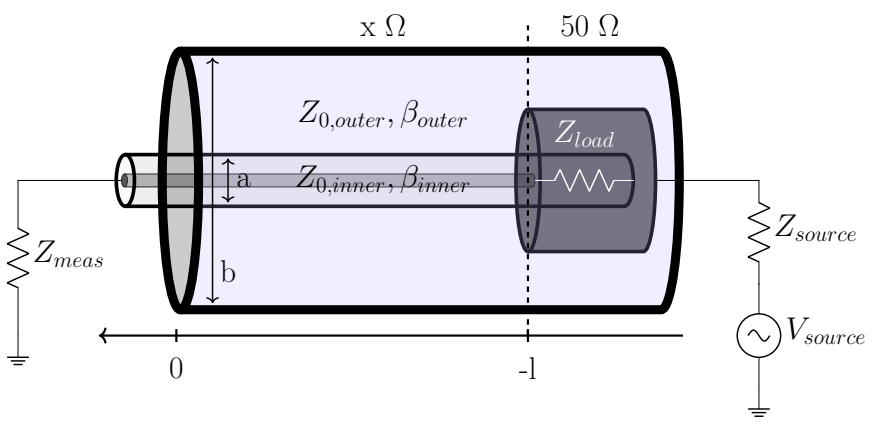

Fig. 1. Drawing of a triaxial tube measurement setup

during the measurement, an approach is made to consider separately the two main sources of the nonideal properties in the system: coupled transmission line effects and wave propagation with imperfect terminations.

\section{A. Coupled transmission line}

Coupled transmission line effects are analyzed first by assuming that the triaxial tube circuits, modeled as transmission lines, are matched. Then, the effect of infinitesimal couplings on far-end cross-talk of a line length $l$ at high frequencies [12]

$$
\begin{aligned}
F_{H F}=\frac{F}{F_{L F}} & =\frac{1-e^{\left(\gamma_{\text {outer }}-\gamma_{\text {inner }}\right) l}}{\left(\gamma_{\text {outer }}-\gamma_{\text {inner }}\right) l} \\
& =\frac{1-e^{j\left(\beta_{\text {outer }}-\beta_{\text {inner }}\right) l}}{j\left(\beta_{\text {outer }}-\beta_{\text {inner }}\right) l},
\end{aligned}
$$

where $F$ is the total far-end cross-talk and $F_{L F}$ is the lowfrequency part of it, is greatly simplified from the unmatched case. The propagation constant $\gamma$ can be simplified to $j \beta$ for lossless lines. The effect does not exist when the propagation speeds on the inner and outer circuits are equal, meaning $\beta_{\text {outer }}=\beta_{\text {inner }}$. For a typical case, the phase constant of the inner circuit $\beta_{\text {inner }}=\omega \sqrt{\mu \varepsilon}$ is slightly larger representing a polymer dielectric inside the cable. Fig. 2 shows the effect of a such increase on $\beta_{\text {inner }}$ in a $50 \mathrm{~cm}$ long triaxial tube.

\section{B. Imperfect terminations}

The effect of imperfect terminations is analyzed by assuming equal propagation speeds on both the inner and the

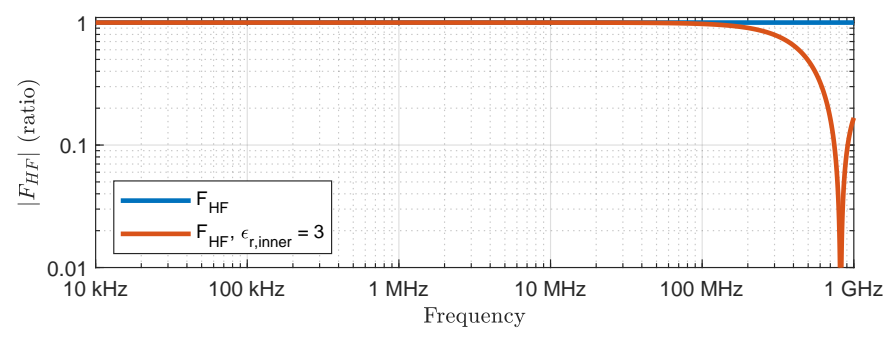

Fig. 2. High-frequency effects on the far-end cross-talk on a $0.5 \mathrm{~m}$ triaxial tube outer transmission line. Characteristic impedance of the outer transmission line [5]

$$
Z_{0, \text { outer }}=\ln \left(\frac{b}{a}\right) \frac{\sqrt{\mu / \varepsilon}}{2 \pi}
$$

is defined as a function of the triaxial tube inner diameter $b$ and the cable shield outer diameter $a$. The dimensions are illustrated in Fig. 1. As the cable under test is varied, $a$ can change causing variation in the characteristic impedance. This impedance variation for two tube diameters $b$ used in this study is shown in Fig. 3. It is clear that the ideal $50 \Omega$ impedance is rarely achieved in a practical measurement. That is true also for the inner transmission line as not all the shielded cables have a controlled characteristic impedance.

From the outer circuit positive voltage wave [5]

$$
V_{\text {outer }}^{+}=V_{\text {source }} \frac{Z_{0, \text { outer }}}{Z_{0, \text { outer }}+Z_{\text {source }}} \frac{e^{-j \beta_{\text {outer }} l}}{1-\Gamma_{l} \Gamma_{g} e^{-2 j \beta_{\text {outer }} l}}
$$

one can calculate the current

$$
I_{\text {outer }}(0)=\frac{2 V_{\text {outer }}^{+}}{Z_{0, \text { outer }}}
$$

at the line end. Now, as the propagation speeds are identical on both transmission lines, the transfer voltage

$$
V_{T}=V_{T}(0)=Z_{T} I_{\text {outer }}(0)
$$

can be simply applied only at the end of the outer transmission line. That yields a simple solution for the measured voltage

$$
V_{\text {meas }}=V_{T} \frac{Z_{\text {meas }}}{Z_{\text {meas }}+Z_{\text {in,inner }}}
$$

at the termination of the inner transmission line. The load impedance $Z_{\text {load }}$ was shifted to the measurement end of the transmission line by impedance transformation

$$
Z_{\text {in,inner }}=Z_{0, \text { inner }} \frac{1+\Gamma_{l, \text { inner }} e^{-2 j \beta_{\text {inner }} l}}{1-\Gamma_{l, \text { inner }} e^{-2 j \beta_{\text {inner }}}} .
$$

The resulting simplified schematic is shown in Fig. 4. The high frequency effect of the impedance mismatch

$$
\begin{aligned}
K_{H F}= & \frac{2 Z_{0, \text { outer }}\left(Z_{l, \text { outer }}+Z_{\text {source }}\right)}{\left(Z_{0, \text { outer }}+Z_{\text {source }}\right)\left(Z_{l, \text { outer }}+Z_{0, \text { outer }}\right)} \\
& \cdot \frac{Z_{\text {meas }}+Z_{\text {load }}}{Z_{\text {meas }}+Z_{\text {in,inner }}} \frac{e^{-j \beta_{\text {outer }} l}}{1-\Gamma_{l} \Gamma_{g} e^{-2 j \beta_{\text {outer }} l}}
\end{aligned}
$$

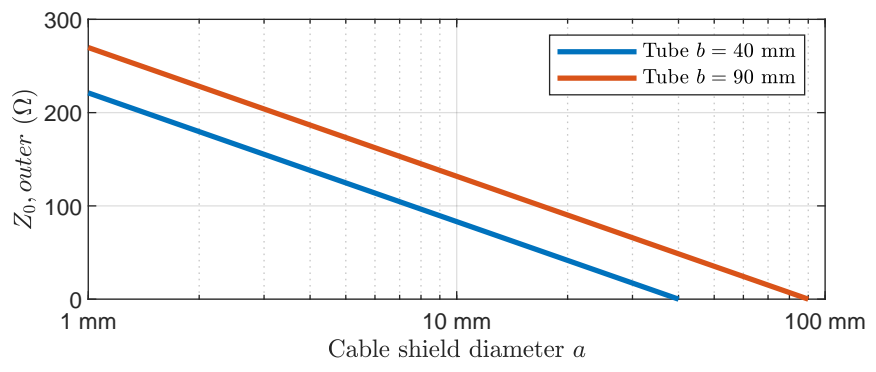

Fig. 3. Characteristic impedance of triaxial tube outer transmission line 


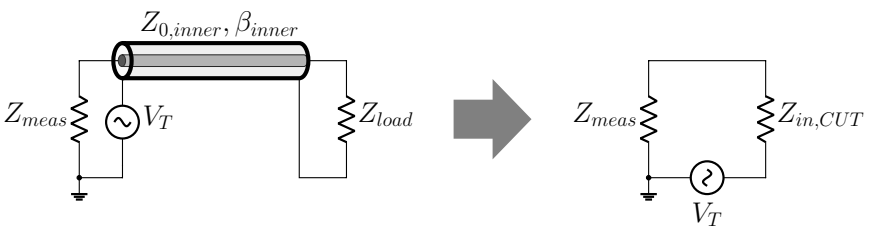

Fig. 4. Simplification of the inner transmission line model

is calculated by dividing the measured voltage $V_{\text {meas }}$ with its low frequency part $V_{\text {meas }}^{L F}$ and setting the source voltage $V_{\text {source }}$ to unity. For a common triaxial setup, the far-end of the outer transmission line is short-circuited and then the high frequency effect coefficient

$$
\begin{aligned}
K_{H F}^{\prime}= & \frac{2 Z_{\text {source }}}{Z_{0, \text { outer }}+Z_{\text {source }}} \frac{Z_{\text {meas }}+Z_{\text {load }}}{Z_{\text {meas }}+Z_{\text {in }, \text { inner }}} \\
& \cdot \frac{e^{-j \beta_{\text {outerl }} l}}{1+\Gamma_{g} e^{-2 j \beta_{\text {outer }} l}}
\end{aligned}
$$

is slightly simplified. The simplest form for the high frequency effect coefficient

$$
K_{H F}^{\prime \prime}=\frac{2 Z_{\text {source }}}{Z_{0, \text { outer }}+Z_{\text {source }}} \frac{e^{-j \beta_{\text {outer }} l}}{1+\Gamma_{g} e^{-2 j \beta_{\text {outer }} l}}
$$

is achieved, when the inner circuit is matched.

Now, using this simplified model, the effect of mismatched terminations can be examined. First, take the situation when the inner circuit is matched and $K_{H F}^{\prime \prime}$ can be used. Picking a few impedance values from a range in Fig. 3, and the effect of changing diameter of the CUT is shown in Fig. 5. Then a situation, where the inner circuit is not anymore matched, is analyzed. In this case $K_{H F}^{\prime}$ is plotted in Fig. 6 sweeping some typical characteristic impedance values of the test cables while holding the outer circuit characteristic impedance at $50 \Omega$. From the results it is easy to see that impedance matching and the value of the characteristic impedance has an effect on the measurement results at lower frequencies than summing of the phase-shifted infinitesimal couplings along the CUT.

\section{Measurement Results}

This section describes the transfer impedance measurement results on two different triaxial cell sizes: inner diameter $b$ of $40 \mathrm{~mm}$ and $90 \mathrm{~mm}$. The measured cable was always $60 \mathrm{~cm}$ long, but the active length varied between the cells: for the smaller cell it was $40 \mathrm{~cm}$ and for the larger cell it was $50 \mathrm{~cm}$. Active length in here refers to the length of the cable, where the measurement current was conducted through the shield. Two special cases of automotive shielded cables were measured together with a double-braided universal cable RG-55/U, all shown in Fig. 7. The first cable is actually not a cable itself, but a braided sheath that is a mix of copper strands and PET fibers. A solid copper wire is used as an inner conductor during the test. The second cable is for high-voltage use with its two inner conductors short-circuited during the test, and covered by an aluminum film shield on top of a copper braid. A picture of the measurement setup

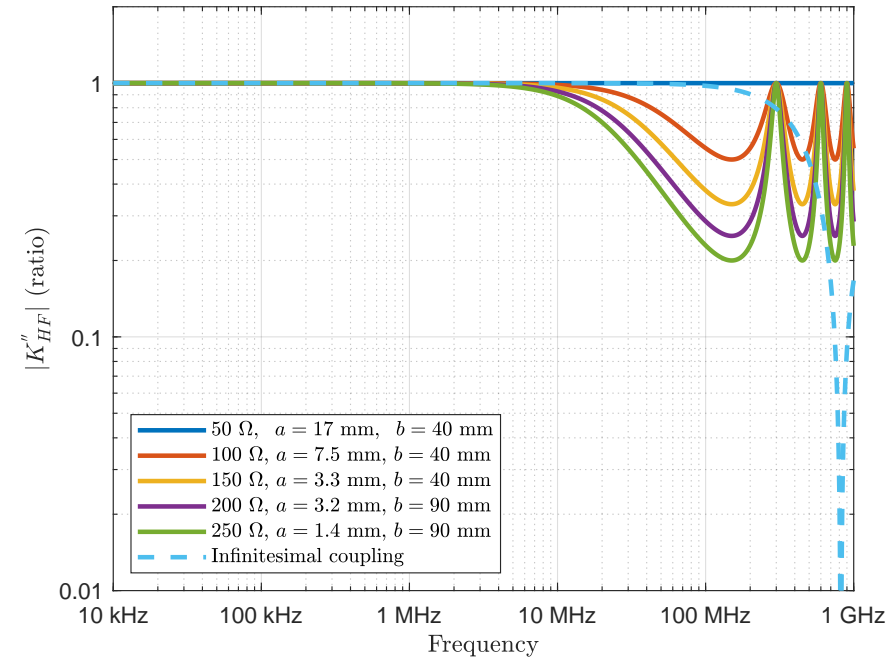

Fig. 5. High-frequency effects $K_{H F}^{\prime \prime}$ of outer line characteristic impedance $Z_{0, \text { outer }}$ variation with different cable shield and triaxial tube diameters ( $a$ and $b$ respectively)

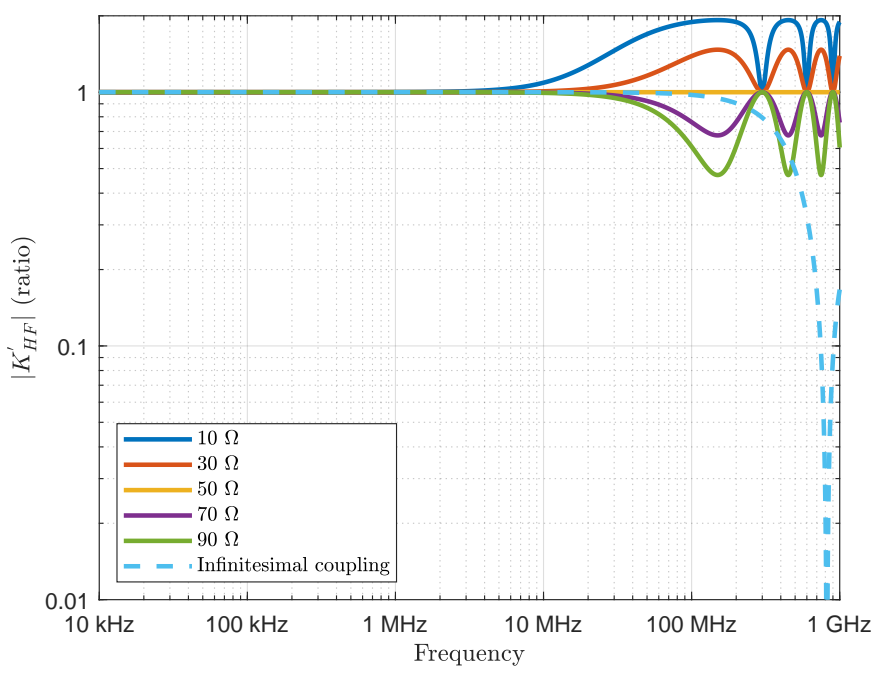

Fig. 6. High-frequency effects $K_{H F}^{\prime}$ of inner cable impedance $Z_{0, \text { inner }}$ variation

for RG-55/U in $90 \mathrm{~mm}$ triaxial tube in Fig. 8 represents well all the used setups. The cables were tested with two configurations: short-circuited (IEC Method C) and terminated with system impedance (IEC Method B). None of the cables had a characteristic impedance that was equal to the system impedance and thus they were not matched.

The braided sheath transfer resistance was $4.0 \pm 0.1 \mathrm{~m} \Omega / \mathrm{m}$ and transfer inductance was $1.8_{-0.2}^{+0.6} \mathrm{nH} / \mathrm{m}$. The results in Fig. 9 show a sufficient agreement of all the four measurement methods. Notable spots are at $2 \mathrm{MHz}$, where all the results start to veer off from the initial inductance line, and around $200 \mathrm{MHz}$, where the measurement configurations with a shorted cable-under-test show a sharp attenuation section, whereas the ones with a terminated cable show more moderate attenuation. 


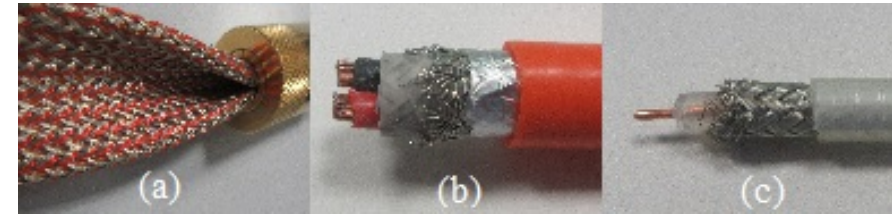

Fig. 7. Measured cables: (a) braided sheath, (b) high voltage cable, and (c) RG-55/U universal cable

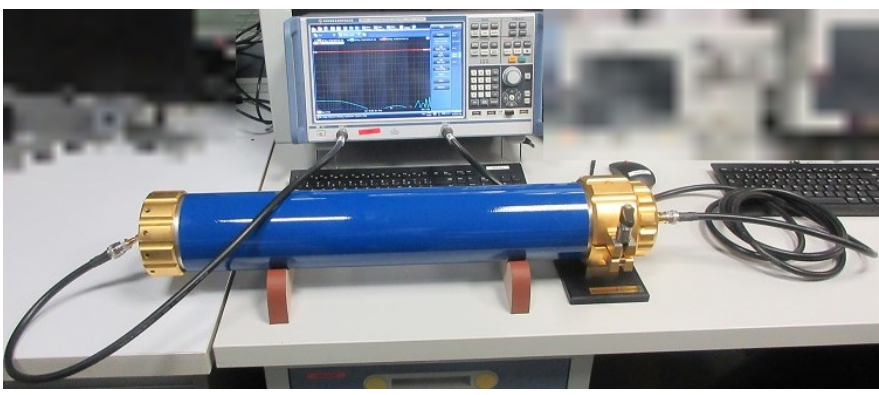

Fig. 8. The $90 \mathrm{~mm}$ triaxial measurement setup with a vector network analyzer

The high-voltage shielded cable transfer resistance was $5.9 \pm 0.2 \mathrm{~m} \Omega / \mathrm{m}$. Transfer inductance could not be determined reliably. This is due to a two-layer shield consisting of a foil on top of a braid. Single transfer inductance definition is not enough to model this shield. As Fig. 10 shows, there was practically no constant inductance that could be detected. The reference line is drawn with $125 \mathrm{pH} / \mathrm{m}$.

The double-braided RG-55/U cable transfer resistance was $8.3_{-0.1}^{+0.2} \mathrm{~m} \Omega / \mathrm{m}$ and transfer inductance was $32 \pm 2 \mathrm{pH} / \mathrm{m}$. The plot in Fig. 11 shows that ideal single transfer inductance definition captures the actual measured transfer inductance better for the double-braided shield used in this cable than for the foil and braid combination on the high-voltage cable.

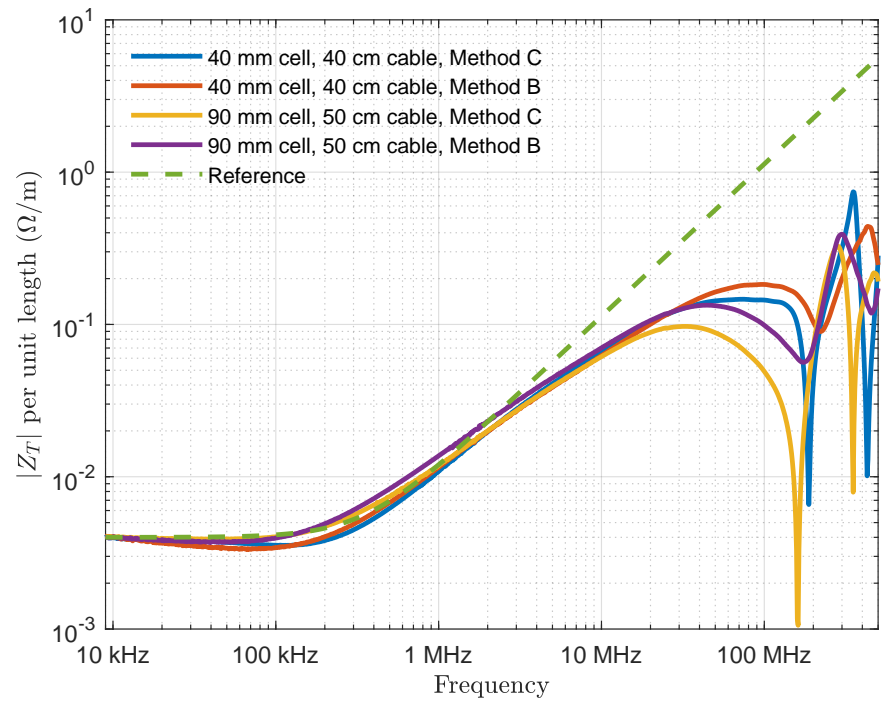

Fig. 9. Transfer impedance measurement results of the braided sheath with a mix of copper strands and PET fibers

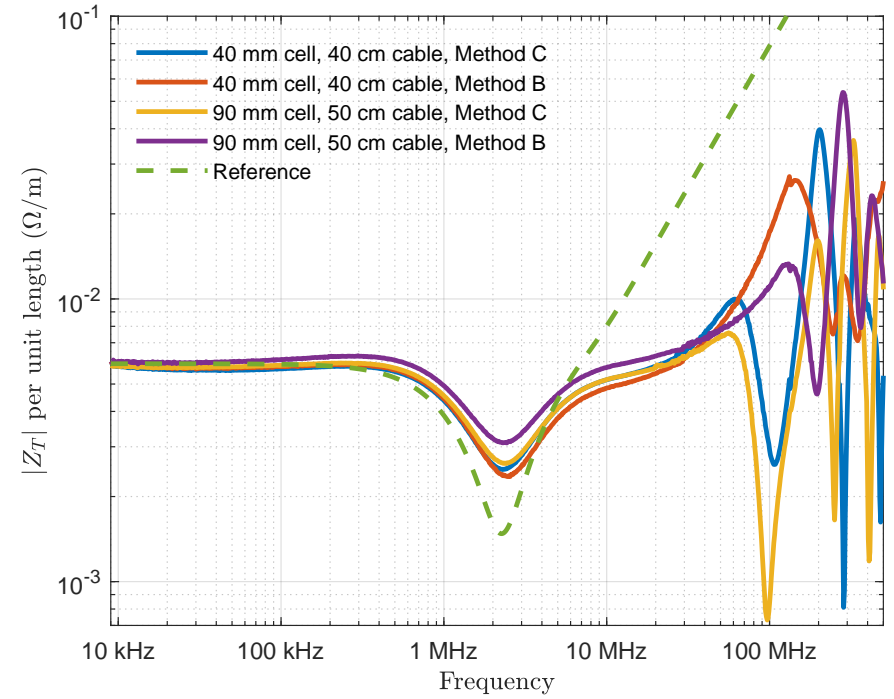

Fig. 10. Transfer impedance measurement results of the high-voltage shielded cable

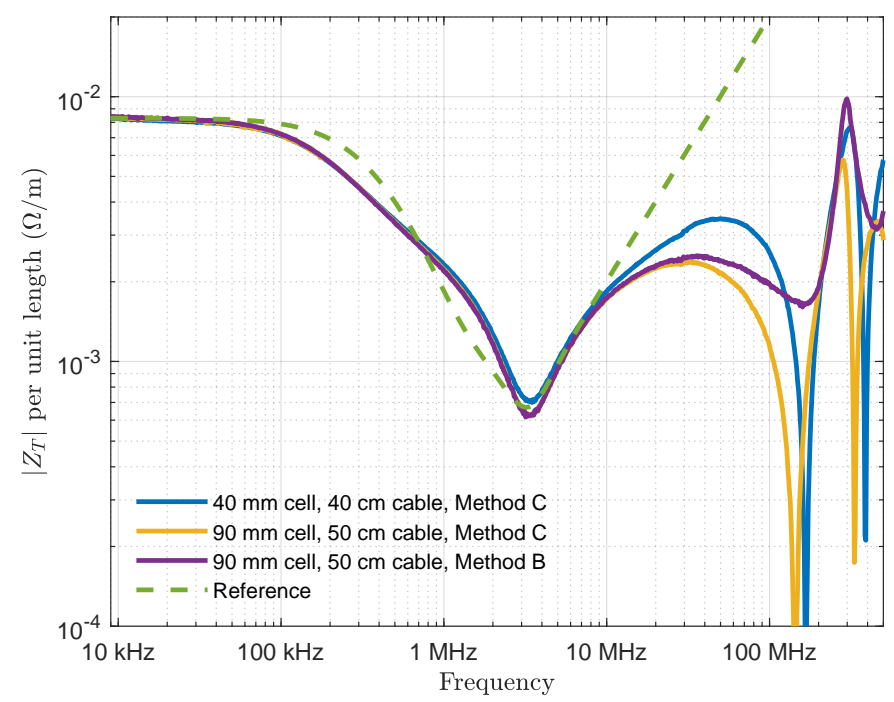

Fig. 11. Transfer impedance measurement results of the RG-55/U cable

Overall, the measurement deviation on determining the transfer resistance between the different configurations was less than $10 \%$, and less than $50 \%$ for transfer inductance in the cases, where the inductance could be determined. Note, that the deviation on these measurements is not normally distributed as it was introduced due to methodological changes in the setup, and a single sample was measured only once in each configuration. This level of precision between the different setups can be considered good.

Measurements with Method C in a $40 \mathrm{~mm}$ cell were chosen to be compared with two models: the simple model introduced in Section II-B and a model available in the IEC 62153 technical specification [9]. To help the comparisons plotted in Fig. 12, a reference line showing the ideal transfer impedance as depicted in (1) was drawn onto every plot. It was drawn 


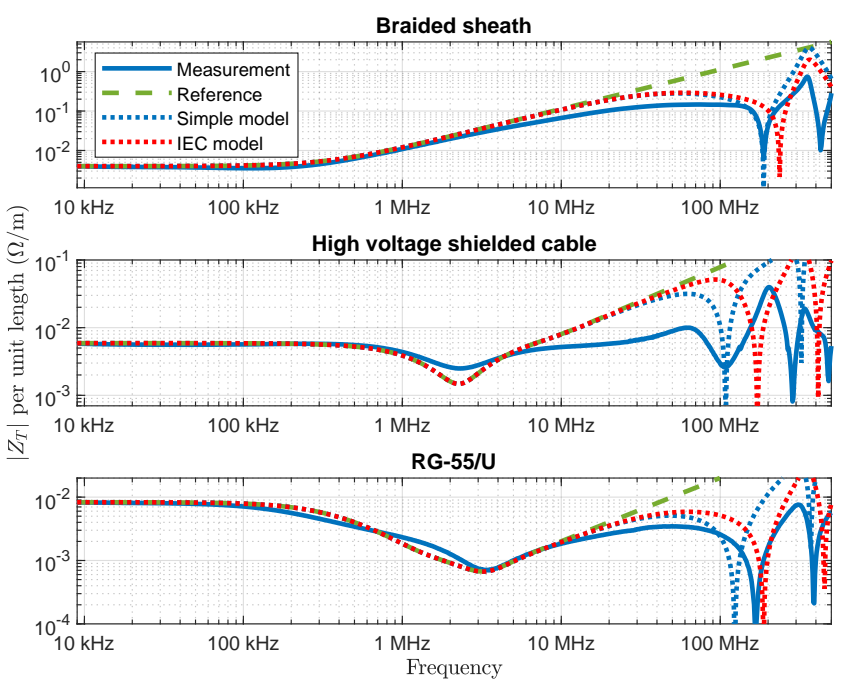

Fig. 12. Comparison of measurement and modeling results with IEC method $\mathrm{C}$ in a tube with inner diameter $b$ of $40 \mathrm{~mm}$

with transfer resistance and inductance values extracted from the measurement results. For the braided sheath, the models do not completely explain the start of the measurement veering off, but the simple model matches very well to the first attenuation spike. At very high frequencies, the models show significantly higher values for the transfer impedance than the measurement. For the high-voltage cable, the ideal transfer impedance was not properly defined by a simple transfer inductance and thus the results from the models were not expected to follow the measurements on that area. However, feeding the ideal transfer impedance to the simple model shows a well placed first attenuation spike. For the RG-55/U cable, the models explain fairly accurately the decrease in the measurement result from $10 \mathrm{MHz}$ onward although the fit of the first attenuation spikes is slightly worse than for the other cables. Actually, here the IEC model matched the measured attenuation figure better.

\section{CONCLUSION}

A simple model to assess the nonideal properties of a triaxial transfer impedance measurement system was derived based on existing literature. The model showed that in a typical measurement setup, the impedance mismatches distort the measurement result more at lower frequencies than the summing of phase-shifted infinitesimal couplings along the cable-under-test. In many cases, the infinitesimal coupling consideration can be left out from the analysis and still an adequate estimation on the validity of the measurement results can be achieved. This approach allows to simplify analysis from the one presented in IEC 62153-4-3 with comparable reliability as the example cases demonstrated.
To improve the model, some additional phenomena should be studied. The measurement setups had overhang of the cableunder-test at the measurement end that was not taken into account. Also, studying the effect of the $50 \Omega$ transmission line part inside the triaxial tube should be done as that was not taken into account during the network analyzer calibration. To address the simplified model accuracy at very high frequencies, an illustrative way of integrating the infinitesimal coupling effect and the impedance mismatches should be studied.

The measurement results showed that in most cases, the inner diameter of the outer cell in the triaxial measurement system does not have a significant effect, when determining the transfer resistance and inductance. In fact, for all the samples used in this study the measurement deviations were on the level that is to be expected between single measurements on the same system. Thus, it will be a matter of taste and practical concerns to choose an appropriate triaxial cell diameter: the cable-under-test is easier to insert in the larger cells, but the larger cells tend to have heavier components and are thus harder to work with.

\section{REFERENCES}

[1] S. A. Schelkunoff, "The electromagnetic theory of coaxial transmission lines and cylindrical shields," Bell System Technical Journal, vol. 13, no. 4, pp. 532-579, Oct. 1934

[2] L. K. Warne, W. L. Langston, L. I. Basilio, and W. A. Johnson, "First principles cable braid electromagnetic penetration model," PIER B, vol. 66, pp. 63-89, 2016.

[3] J. Verpoorte, H. Schippers, and J. L. Rotgerink, "Advanced models for the transfer impedance of metal braids in cable harnesses," in 2018 IEEE International Symposium on Electromagnetic Compatibility and 2018 IEEE Asia-Pacific Symposium on Electromagnetic Compatibility (EMC/APEMC). Singapore: IEEE, May 2018, pp. 187-192.

[4] E. Vance, "Shielding effectiveness of braided-wire shields," IEEE Trans. Electromagn. Compat., vol. 17, no. 2, pp. 71-77, May 1975.

[5] D. M. Pozar, Microwave Engineering, 3rd ed. Hoboken, NJ: J. Wiley, 2005.

[6] T. Kley, "Optimized single-braided cable shields," IEEE Trans. Electromagn. Compat., vol. 35, no. 1, pp. 1-9, Feb. 1993.

[7] A. Mushtaq, A. Zeichner, and S. Frei, "Analysis of the shielding characteristics of cable-plug systems for electric vehicles - Analyse der schirmungseigenschaften von kabel-stecker-systemen für elektrische fahrzeuge," Elektromagnetische Vertraeglichkeit in der KFZ-Technik, GMM-Fachtagung 2014, 2014.

[8] J. L. Rotgerink, H. Schippers, and J. Verpoorte, "Multi-conductor transmission line modelling of transfer impedance measurement methods," in 2017 International Symposium on Electromagnetic Compatibility EMC EUROPE. Angers, France: IEEE, Sep. 2017, pp. 1-7.

[9] IEC TS 62153-4-1, Metallic Communication Cable Test Methods - Part 4-1: Electromagnetic Compatibility (EMC) - Introduction to Electromagnetic Screening Measurements, 2014.

[10] T. Kley, "Measuring the coupling parameters of shielded cables," IEEE Trans. Electromagn. Compat., vol. 35, no. 1, pp. 10-20, Feb. 1993.

[11] IEC 62153-4-3, Metallic Communication Cable Test Methods - Part 43: Electromagnetic Compatibility (EMC) - Surface Transfer Impedance - Triaxial Method, 2013.

[12] S. A. Schelkunoff and T. M. Odarenko, "Crosstalk between coaxial transmission lines," Bell System Technical Journal, vol. 16, no. 2, pp. 144-164, Apr. 1937. 